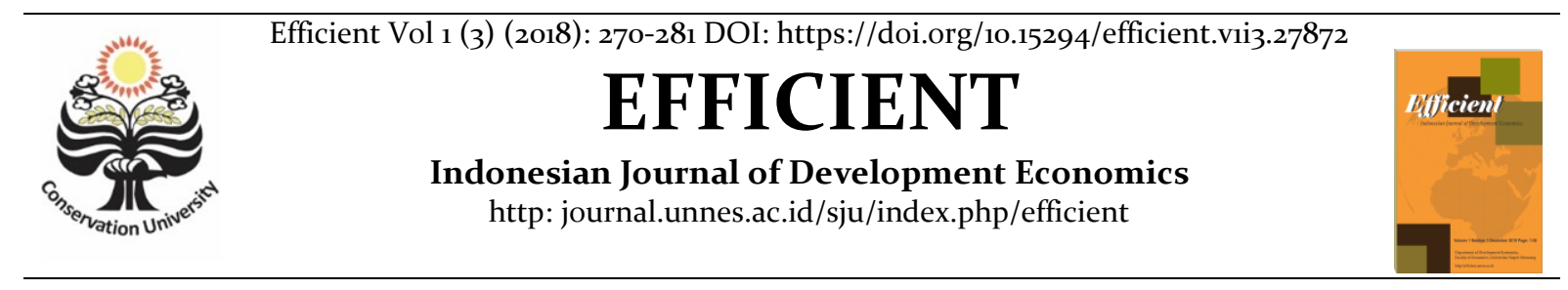

\title{
Evaluasi Implementasi Kebijakan Program Indonesia Pintar Di SDN Magersari Kabupaten Rembang
}

\author{
Didik Mulya Setyawan
}

Jurusan Ekonomi Pembangunan, Fakultas Ekonomi, Universitas Negeri Semarang

Permalink/DOI: https://doi.org/10.15294/efficient.vii3.27872

Received: April 2018; Accepted: July 2018; Published: October 2018

\begin{abstract}
One of the current program thaa is being worked by government is Program Indonesia Pintar (PIP) is a program that hopefully we can expect to decrease problems about education in Indonesia. Program Indonesia Pintar (PIP) is an aid in form of cash from government aim at students whose parents can not pay the cost of education. The analysis method of this resarch is qualitative descriptive to identify the implementation of Program Indonesia Pintar (PIP), also the obstacle when doing this program in Rembang Regency. The result of this reaearch found that the implementation of Program Indonesia Pintar (PIP) in Rembang Regency has been done well with proof that it has been distributed to all students whose parents can pay the cost of education so that their children can go to school up to high school. All the steps of Program Indonesia Pintar (PIP) has been done starts from socialization, opinion, verification, and the distribution of the cash money which person requires or not, it's because of finance constraint. The obstacle is the distribution of this program to people it's because people who can pay for the cost of education of their children so they can go to up to high school, that means people can not use the cash money for anything but educational stuff, or for families who do not actually need and deserve the money from Program Indonesia Pintar (PIP) do not have the chance to apply for thisaid.
\end{abstract}

Keywords : Implementation, Program of Indonesia Pintar

\begin{abstract}
Abstrak
Program yang sedang dijalankan oleh pemerintah saat ini yaitu salah satunya Progam Indonesia Pintar (PIP) merupakan program yang diharapkan dapat mengurai permasalahan perekonomian terkait dengan bidang pendidikan. Program Indonesia Pintar (PIP) adalah bantuan berupa uang tunai dari pemerintah yang diberikan kepada peserta didik yang orang tuanya tidak dan atau kurang mampu membiayai pendidikannya.Analisis yang digunakan terdiri dari analisis deskriptif kualitatif untuk mengidentifikasi pelaksanaan Progam Indonesia Pintar (PIP), serta kendala yang ditemukan selama pelaksanaan Progam Indonesia Pintar (PIP) di Kabupaten Rembang. Hasil penelitian menemukan bahwa pelaksanaan Progam Indonesia Pintar (PIP)di Kabupaten Rembang telah dilaksanakan dengan baik yang dibuktikan dengan telah disalurkannya danaProgam Indonesia Pintar (PIP)bagi warga tidak mampu untuk keperluan sekolah anaknya hingga mencapai pendidikan menengah. Semua tahapan Progam Indonesia Pintar (PIP)sudah dilaksanakan mulai dari sosialisasi, usulan, verifikasi hingga penyaluran danaProgam Indonesia Pintar (PIP). Kendala yang ditemukan seperti belum dapat tersalurkannya dana ke masyarakat yang memang benar-benar membutuhkan atau salah dalam penyaluran kepada masyarakat yang sebenarnya tidak berhak, hal ini disebabkan karena kendala administrasi. Adapun saran dari penelitian ini diantaranya bahwa masyarakat hendaknya memaknai program ini sebagai salah satu upaya pemerintah dalam memberikan bantuan pendidikan kepada siswa hingga jenjang menengah, sehingga tidak mengambil keuntungan dari program ini untuk kepentingan-kepentingan yang diluar keperluan sekolah, atau bahkan bagi keluarga yang tidak seharunya menerima bantuan dari Progam Indonesia Pintar (PIP) tidak berupaya untuk mengajukan bantuan.
\end{abstract}

\section{Kata Kunci : Penerapan, Program Indonesia Pintar}

How to Cite: Setyawan, D. (2018). Evaluasi Implementasi Kebijakan Program Indonesia Pintar Di SDN Magersari Kabupaten Rembang. EFFICIENT Indonesian Journal of Development Economics, 1(3), $270-281$. https://doi.org/10.15294/efficient.vii3.27872

(C) 2018 Semarang State University. All rights reserved

\footnotetext{
"बAlamat Korespondensi :

Alamat: Gedung L2 Lantai 2 FE Unnes

Kampus Sekaran, Gunungpati, Semarang, 50229

E-mail: efficientjournal@gmail.com
}

ISSN 


\section{PENDAHULUAN}

Pendidikan sangat berguna bagi kehidupan dimasa yang akan datang. Pendidikan tidak lepas dengan proses belajar mengajar. Banyak hal yang didapatkan dari proses belajar. Hal-hal yang didapatkan dari proses belajar yaitu ilmu, kebudayaan, etika, bahasa dan lainlain. Dengan adanya pendidikan tujuan negara yaitu "mencerdaskan kehidupan bangsa" dapat tersalurkan.

Pemerintah memiliki tanggung jawab yang besar mengatur dan mengurus bangsanya.Luasnya wilayah, kesenjangan ekonomi dan persebaran jumlah penduduk di Indonesia menjadi salah satu hambatan untuk pemerataan pendidikan.Sehingga pemerintah pusat memberikan wewenang untuk pemerintah daerah dalam membantu mengurai masalah yang ada di daerah masing-masing.

Sebagaimana pemerintah pusat telah melimpahkan wewenang ke pemerintah daerah, maka dari itu pemerintah daerah memiliki tanggung jawab terhadap daerah masingmasing.Setiap daerah memiliki perbedaan dalam segi sumber daya manusia. Sehingga setiap daerah memiliki cara masing-masing untuk mengantisipasi permasalahan yang ada di daerahnya.

Sistem pendidikan Indonesia menyesuaikan dengan model otonomi (Noor, 2013: 6). Kebijakan otonomi daerah dalam penyelenggaraan pendidikan dengan tetap mengacu kepada rambu-rambu atau standar-standar yang telah ditetapkan secara nasional. Implementasi kebijakan otonomi daerah yang didasarkan pada Undang-Undang Nomor 32 Tahun 2004, Undang-Undang Nomor 23 Tahun 2014 dan disempurnakan kembali di Undang-
Undang Nomor 9 Tahun 2015 yaitu memutuskan kebijakan secara mandiri, dahulu kewenangan berada di pusat namun sekarang telah diserahkan kepada daerah provinsi, kabupaten/ kota.

Kebijakan pendidikan pusat yang diturunkan kepada daerah tentang wajib belajar 9 tahun diatur dalam Peraturan Pemerintah Republik Indonesia Nomor 47 Tahun 2008 pasal 1 ayat (1) yang dimaksud wajib belajar adalah program pendidikan minimal yang harus diikuti oleh warga Negara Indonesia atas tanggung jawab pemerintah dan pemerintah daerah.

Program yang sedang dijalankan oleh pemerintah saat ini yaitu salah satunya Progam Indonesia Pintar (PIP) merupakan program yang harapkan dapat mengurai permasalahan perekonomian terkait dengan bidang pendidikan.Program Indonesia Pintar (PIP) adalah bantuan berupa uang tunai dari pemerintah yang diberikan kepada peserta didik yang orang tuanya tidak dan atau kurang mampu membiayai pendidikannya.Program ini diharapkan dapat menjadi gerbang menuju pendidikan yang setara.

Berdasarkan Peraturan Menteri

Pendidikan dan Kebudayaan Republik Indonesia Nomor 12 tahun 2015 pasal 1 ayat 1 Program Indonesia Pintar (PIP) adalah bantuan yang berupa uang tunai dari pemerintah yang diberikan kepada peserta didik yang orang tuanya tidak dan atau kurang mampu membiayai pendidikannya, sebagai kelanjutan dan perluasan sasaran dari program Bantuan Siswa Miskin (BSM). Pada dasarnya tujuan dari Program Indonesia Pintar (PIP) meliputi untuk merintis wajib belajar 12 tahun, mengurangi peserta didik putus sekolah akibat kesulitan ekonomi dan menarik kembali peserta didik untuk melanjutkan pendidikan. Selain itu sasaran dari program ini 
yaitu peserta didik yang sudah mempunyai Kartu Perlindungan Sosial (KPS) dan dari keluarga peserta Program Keluarga Harapan (PKH). Proses pelaksanaan Program Indonesia Pintar (PIP) dimulai Direktorat teknis Kemendikbud ke Dinas Pendidikan Kabupaten/ Kota diteruskan ke sekolah dan di tujukan ke siswa.

Tabel 1. Sasaran Dana PIP Tahun 2015

\begin{tabular}{ll}
\hline $\begin{array}{l}\text { Jenjang } \\
\text { Pendidiakan }\end{array}$ & $\begin{array}{l}\text { Sasaran } \\
\text { (jumlah peserta) }\end{array}$ \\
\hline SD & 10.470 .610 \\
SMP & 4.249 .607 \\
SMA & 1.353 .515 \\
SMK & 1.846 .538 \\
Jumlah & 17.920 .270 \\
\hline
\end{tabular}

Sumber: Peraturan Menteri Pendidikan dan Kebudayaan No. 12 Tahun 2015.

Berdasarkan tabel 1 siswa SD merupakan sasaran terbanyak dari program ini. Siswa SD yang telah terdaftar dalam Program Keluarga Harapan (PKH) atau Bantuan Siswa Miskin (BSM) berhak mendapatkan bantuan dari Program Indonesia Pintar sehingga harapannya dapat menunjang pendidikan dasar dan dapat membantu meringankan beban orang tua siswa.

\section{METODOLOGI PENELITIAN}

Pendekatan yang digunakan dalam penelitian ini adalah deskriptif kualitatif. Pendekatan dengan kualitatif dimaksudkan untuk memahami fenomena sosial melalui gambaran secara menyuluruh dan memperbanyak pemahaman yang mendalam.(Sugiyono, 2012). Data primer merupakan data yang diperoleh secara langsung dari sumber pertama yang mengetahui masalah yang akan dikaji dan bersedia memberi data atau informasi yang diperlukan. Terkait dengan problematika penelitian, maka data primer diperoleh dari pejabat atau pegawai negeri sipil yang bertugas di Dinas Pendidikan Kabupaten Rembang Ibu Kusrini, S.Pd sebagai Kepala Seksi Kurikulum TK/ SD. Selain itu, data primer dalam penelitian ini diperoleh dari Kepala Sekolah SD N Magersari Ibu Luhur Sudaryanti, S.Pd dan wali murid SD N Magersari.

Menurut Bogdan dalam Sugiyono (2012: 334) Analisis data adalah proses mencari dan menyusun secara sistematis data yang diperoleh dari hasil wawancara, catatan lapangan, bahan-bahan lain, sehingga dapat mudah dipahami dan temuannya dapat diinformasikan kepada orang lain.

Analisis data dilakukan dengan mengorganisasikan data, menjabarkannya kedalam unit-unit, melakukan sintesa, menyusun kedalam pola, memilih mana yang penting dan yang akan dipelajari dan membuat kesimpulan yang dapat diceritakan kepada orang lain.

Model analisis data yang digunakan dalam penelitian ini menggunakan model Miles and Huberman (1984) dalam (Sugiyono, 2013: 337-338), yaitu pengumpulan data (data collection), reduksi data (data reduction), penyajian data (data display) dan kesimpulan/ verifikasi (conclusion drawing/verification)

\section{HASIL DAN PEMBAHASAN}

\section{Pelaksanaan Program Indonesia Pintar di Kabupaten Rembang}

Responden penelitian ini terdiri dari Kepala Seksi Kurikulum TK/ SD Dinas Pendidikan Kabupaten Rembang, Kepala SD N Magersari Kabupaten Rembang dan wali murid SDN Magersari. Profil wal 
murid di SD N Magersari Kabupaten Rembang terdiri dari 25 responden dengan keterangan karakteristik sebagai berikut

Tabel 2. Karakteristik Wali Murid SDN Magersari

\begin{tabular}{lll}
\hline Karakteristik & Frekuensi & Persentase \\
\hline Pendidikan & & \\
SD & 6 & $24 \%$ \\
SMP & 14 & $56 \%$ \\
SMA & 5 & $20 \%$
\end{tabular}

\begin{tabular}{lll}
\hline Karakteristik & Frekuensi & Persentase \\
\hline Pekerjaan & & \\
Nelayan & 8 & $32 \%$ \\
Buruh bangunan & 5 & $20 \%$ \\
Petani & 12 & $48 \%$ \\
\hline
\end{tabular}

Sumber: Data SD N Magersari (diolah)

Berdasarkan tingkat pendidikan wali murid diketahui sebagian besar berpendidikan SMP atau sederajat dengan jenis pekerjaan yang terbanyak adalah sebagai petani. Dan Berkaitan dengan pelaksanaan Program Indonesia Pintar (PIP) di Kabupaten Rembang sudah berjalan dengan baik.

Pelaksanaan Program Indonesia Pintar (PIP) berdasarkan keterangan Kepala SD N Magersari Kabupaten Rembang

Berdasarkan keterangan dari Kepala SD N Magersari Kabupaten Rembang Ibu Luhur Sudaryanti, S.Pd bahwa pelaksanaan Program Indonesia Pitar (PIP) telah berjalan dengan baik, sebagaimana keterangan kepala SD N Magersari Kabupaten Rembang sebagai berikut:

"Ya, sudah berlangsung dengan baik, artinya bahwa pelaksanaan program PIP telah dilaksanakan di
Kabupaten Rembang sesuai dengan petunjuk teknis pelaksanaannya"

(Wawancara, 5 Desember 2016)

Pelaksanaan Program Indonesia Pintar (PIP) pada satuan tingkatan pendidikan juga diatur dalam Pasal 14 yaitu pengelola Program Indonesia Pintar (PIP) 2015 tingkat satuan pendidikan adalah sekolah/ SKB/ PKBM/ Lembaga Kursus Pelatihan (LKP/ satuan pendidikan nonformal lainnya) dan Balai Latihan Kerja (BLK) yang ditunjuk dengan rincian tugas sebagai berikut:

1. Memasukkan daftar nama peserta didik dalam data pokok pendidikan (Dapodik);

2. Mengusulkan peserta didik calon peserta dana BSM/ PIP;

3. Memantau proses pengambilan dana BSM/ PIP;

4. Menerima anak usia 6 (enam) sampai dengan 21 (dua puluh satu) tahun pemegang KIP yang belum/ putus sekolah.

Langkah-langkah pelaksanaan tersebut sesuai dengan apa yang sudah dilaksanakan di Kabupaten Rembang. Berdasarkan hasil wawancara dengan kepala sekolah SD N Magersari Kabupaten Rembang Ibu Luhur Sudaryanti, S.Pd langkah-langkah penerapan Program Indonesia Pintar (PIP) antara lain:

1. Pendataan siswa yang punya KIP/ KPS

2. Pengiriman data ke Dinas Pendidikan

3. Pencairan dana PIP

Program Indonesia Pintar (PIP) ini tentunya sangat membantu bagi orang tua terutama yang tidak mampu guna membantuk biaya sekolah seperti pembelian 
seragam ataupun buku pelajaran. Sebagaimana disebutkan oleh kepala sekolah SD N Magersari Kabupaten Rembang Ibu Luhur Sudaryanti, S.Pd bahwa:

"Sangat membantu, terutama bagi siswa yang kurang mampu"

(Wawancara, 5 Desember 2016)

Siswa dengan orang tua yang kurang mampu bisa sangat terbantu dengan Program Indonesia Pintar (PIP) ini, sehingga diharapkan tidak ada anak yang terpaksa putus sekolah karena kekurangan biaya. Oleh karena itu perlu penyaluran dana Program Indonesia Pintar (PIP) ini dengan benar sehingga tepat sasaran. Berkaitan dengan pemberian dana Program Indonesia Pintar (PIP) terhadap sasaran yang tepat, menurut keterangan kepala SD N Magersari Ibu Luhur Sudaryanti, S.Pd menyebutkan bahwa:

"Pemberian dana Program Indonesia Pintar (PIP) ini sudah tepat sasaran"

(Wawancara, 5 Desember 2016)

Informan menjelaskan keyakinannya karena memang dilakukan verifikasi data terhadap calon penerima dana Program Indonesia Pintar (PIP) sebelumnya. Pelaksanaan verifikasi data dibutuhkan untuk dapat menjaring peserta Program Indonesia Pintar (PIP) sesuai dengan ketentuan program yang diterangkan dalam pedoman petunjuk teknis Program Indonesia Pintar (PIP).Data yang sudah diserahkan oleh calon peserta harus diteliti dengan cermat agar mematuhi standar persyaratan yang dibutuhkan. Oleh karena itu salah satu tahapan dalam program Program Indonesia Pintar (PIP) adalah verifikasi data. Berdasarkan keterangan dari Kepala SD N Magersari Kabupaten Rembang Ibu Luhur Sudaryanti, S.Pd, berkaitan verifikasi data pada awalnya dari pihak sekolah memberikan sosialisasi tentang Porgram Indonesia Pintar (PIP), kemudian setelah wali murid memahami, kemudian berinisiatif, yaitu jika merasa dirinya tidak mampu maka datang ke sekolah dan mengajukan permohonan dengan melengkapi persyaratan. Selanjutnya pihak sekolah akan meneruskan ke dinas pendidikan.

Verifikasi yang dilakukan oleh pihak sekolah adalah dengan memeriksa satu persatu kelengkapan persyaratan, kemudian sekolah mengusulkan peserta didik calon penerima Program Indonesia Pintar (PIP) yang memenuhi persyaratan, disahkan dengan surat pernyataan sekolah penerima Program Indonesia Pintar (PIP) yang ditandatangani oleh kepala sekolah.

Verifikasi data siswa ini juga sebenarnya terintegarasi dengan program Kartu Indonesia Pintar (KIP), sehingga bagi siswa yang memang orang tuanya kurang mampu tetapi belum mempunyai Kartu Indonesia Pintar (KIP) maka akan didata dengan seksama kemudian dilaporkan ke Dinas Pendidikan. Seperti pernyataan kepala sekolah SD N Magersari Ibu Luhur Sudaryanti, S.Pd bahwa:

"Mendata siswa yang kurang
mampu tetapi belum mampunyai
Kartu Indonesia Pintar (KIP)
dilaporkan ke dinas pendidikan"
(Wawancara, 5 Desember 2016)

Sehingga harapannya melalui upaya ini diharapkan Program PIP ini benarbenar dapat menyentuh kepada mereka yang benar - benar membutuhkan. 
Pelaksanaan Program Indonesia Pintar (PIP) berdasarkan keterangan Wali Murid SD N Magersari Kabupaten Rembang

Suksesnya Program Indonesia Pintar (PIP) sebagai salah satu program pemerintah untuk meningkatkan keterjangkauan pendidikan bagi seluruh anak usia sekolah juga tergantung kepada pemahaman orang tua wali murid tentang program ini. Orang tua yang memahami Program Indonesia Pintar (PIP) ini akan berupaya menyesuaikan berbagai persyaratan yang harus dilengkapi serta memahami bagaimana langkah yang bisa dilakukan guna mendapatkan dana Program Indonesia Pintar (PIP) untuk keperluan sekolah anaknya.

Hasil penelitian ini menemukan bahwa pelaksanaan Program Indonesia Pintar (PIP) di Kabupaten Rembang sudah berjalan, namun demikian sebenarnya keberadaan Program Indonesia Pintar (PIP) ini mendapat tanggapan yang berbeda dari berbagai warga masyarakat. Terdapat dua kategori pemahaman orang tua wali murid terhadap Program Indonesia Pintar (PIP).Sebagian besar telah memahami Program Indonesia Pintar (PIP) yaitu sebanyak 11 orang tua wali murid (44\%) dan yang tidak memahami tentang Program Indonesia Pintar (PIP) sebanyak 14 orang tua wali murid (56\%). Berdasarkan keterangan dari wali murid yang belum memahami progam Program Indonesia Pintar mengatakan:

"Ya saya sebenarnya belum paham sepenuhnya tentang Program Indonesia Pintar (PIP) itu mas" (Wawancara, 3 Desember 2016)
Sementara keterangan dari wali murid lain menyebutkan:

"Ya saya memahami, karena Program Indonesia Pintar (PIP) adalah bantuan untuk siswa kurang mampu" (Wawancara, 3 Desember 2016)

Ketidaksamaan pemahaman antar warga masyarakat tentang Program Indonesia Pintar (PIP) ini sebenarnya tidak terlepas dari semua pihak yang memiliki kaitan dengan Program Indonesia Pintar (PIP) ini dalam melakukan sosialisasi. Namun dengan adanya Program Indonesia Pintar (PIP) ini masyarakat merasa sangat terbantu, karena mendapatkan dana untuk keperluan sekolah anak-anaknya. Sebagaimana dinyatakan oleh salah satu orang tua wali murid:

"Saya sangat terbantu adanya Program Indonesia Pintar (PIP) ini, karena PIP ini kan memang sasarannya untuk program Bantuan Siswa Miskin (BSM), sehingga mencegah peserta didik dari kemungkinan putus sekolah atau tidak dapat melanjutkan pendidikan akibat kesulitan ekonomi"

(Wawancara, 3 Desember 2016)

Keterangan tersebut menunjukkan bahwa begitu pentingnya Program Indonesia Pintar (PIP) ini sebagai salah satu upaya untuk membantu siswa miskin agar jangan sampai putus sekolah. Sehingga program ini manfaatnya sangat besar bagi warga masyarakat miskin terutama yang tinggal di pedesaan. Penerima PIP tidak diperkenankan menggunakan dana tersebut untuk tujuan yang tidak berhubungan dengan kegiatan pendidikan, antara lain: judi, narkoba, miras dan tindakan negatif lainnya.

Sebagaimana dinyatakan oleh orang tua wali murid sebagai berikut 
"Ya, bantuan tersebut berguna untuk keperluan sekolah, misalkan peralatan/ perlengkapan sekolah, seperti buku, seragam dan lainnya" (Wawancara, 3 Desember 2016)

Keterangan wali murid lainnya:

"Ya, karena digunakan untuk memenuhi kebutuhan sekolah anak"

(Wawancara, 3 Desember 2016)

Berdasarkan keterangan di atas maka sudah selayaknya bagi orang tua yang menerima bantuan dari Program Indonesia Pintar (PIP) untuk dapat bertindak secara bijak dalam penggunaan dana dari Program Indonesia Pintar (PIP). Dana yang diberikan melalui Program Indonesia Pintar (PIP) ini adalah berbentuk uang tunai sehingga ada kemungkinan terjadi penyelewengan penggunaan dana Program Indonesia Pintar (PIP) bukan untuk keperluan sekolah saja.

Pelaksanaan Program Indonesia Pintar (PIP) berdasarkan keterangan Kepala Seksi Kurikulum TK/ SD Dinas Pendidikan Kabupaten Rembang

Program Indonesia Pintar (PIP) ini sebenarnya adalah kelanjutan dari program-program sebelumnya, yaitu kaitan tentang dana bantuan pendidikan bagi warga miskin. Kepala Seksi Kurikulum TK/ SD Dinas Pendidikan Kabupaten Rembang Ibu Kusrini, S.Pd menyatakan bahwa sebenarnya program seperti Program Indonesia Pintar telah berjalan sejak 2007. Program KIP (Kartu Indonesia Pintar) tersebut menggantikan program KPS (Kartu Perlindungan Sosial), tepatnya program BSM (Bantuan Siswa Miskin).
Pelaksanaan Program Indonesia Pintar (PIP) di Kabupaten Rembang sudah berjalan dengan baik dan pelaksanaannya sebenarnya tidak terlalu sulit karena tinggal melanjutkan program sebelumnya. Jadi program Program Indonesia Pintar (PIP) di Kabupaten Rembang ini sebagai pelaksanaan dari ketentuan yang diatur di atasnya seperti Keputusan Presiden tentang Program Indonesia Pintar (PIP) serta Permendikbud Nomori2 Tahun 2005 tentang Program Indonesia Pintar.

Pelaksanaan Program Indonesia Pintar (PIP) di Kabupaten Rembang juga telah dilakukan secara merata sesuai dengan kuota yang ditentukan. Keterangan Kepala Seksi Kurikulum TK/ SD Dinas Pendidikan Kabupaten Rembang Ibu Kusrini, S.Pd:

"Untuk pemerataan PIP sudah merata diseluruh Kabupaten Rembang data yang kami punya jumlah SD 51.151 seKabupaten Rembang, anak yang dapat 43.0oo dan ini tidak masuk akal, mengapa dibilang tidak masuk akal artinya di Kabupaten Rembang itu 85\% itu miskin semua. Jadi 1 tahap bisa mencapai 12.000 anak padahal 1 tahun bisa sampai 16 tahap, bertahap 7.00o, 10.000 setelah itu di rekap tahun 2015 ada 43.000 anak artinya masyarakat Kabupaten Rembang manakala ada namanya bantuan mereka mengaku semua miskin minta di usulkan. Jadi sebenarnya tidak masuk akal "masak orang Rembang hampir semua miskin" karena kami punya tanggung jawab evaluasi dan monitoring.Kami monitoring ke beberapa sekolah seminim-minimalnya per kecamatan kami kunjungi monitoring secara berkala. Ada yang 1 sekolah dapat semua karena kepala sekolah takut kepada masyarakat dan dinas untuk mengatasinya kalau ada apa-apa kepala sekolah bertanggung jawab, 
Kami sudah mengadakan sosialisasi (Wawancara, 13 Desember 2016)

Dinas Pendidikan dalam upaya menjaga agar Program Indonesia Pintar (PIP) dapat tersalurkan sesuai dengan sasarannya maka Dinas Pendidikan melakukan monitoring secara berkala ke semua wilayah Kabupaten Rembang. Penyaluran dana Program Indonesia Pintar (PIP) juga disalurkan langsung kepada penerimanya melalui Bank. Sebagaimana dinyatakan Kepala Seksi Kurikulum TK/ SD Dinas Pendidikan Kabupaten Rembang Ibu Kusrini, S.Pd:

"Teknis pencairan masyarakat langsung ke bank penyalur, dengan adanya seperti ini dana tersebut betulbetul tersalurkan ke masyarakat, dulu pernah lewat sekolah tapi rawan penyelewengan dana tersebut"

(Wawancara, 13 Desember 2016)

Pihak Dinas Pendidikan juga melalukan sosialisasi terhadap Program Indonesia Pintar (PIP) ini sehingga dapat dimengerti oleh semua satuan pendidikan yang ada di Wilayah Kabupaten Rembang. Berdasarkan hasil wawamcara dengan Kepala Seksi Kurikulum TK/ SD Dinas Pendidikan Kabupaten Rembang Ibu Kusrini, S.Pd sebagai berikut:

"Kita tidak mengumpulkan sekolah, namun kita memberikan informasi tentang PIP ini. Jadi sebenarnya kalau yang aktif ya sudah bisa mengakses melalui website dinas. Jadi sudah ada informasiinformasi.Dinas pendidikan secara tidak langsung sudah menginformasikan melalui website. Kita menegaskan saja dan menindaklanjuti jika sekolah ingin mengusulkan siswanya. Sekolah yang merespon dan memberikan berkas, lalu berkasnya kita periksa kekurangankekurangnnya"

(Wawancara, 13 Desember 2016)

Lebih lanjut lagi pihak Kepala Seksi Kurikulum TK/ SD Dinas Pendidikan Kabupaten Rembang Ibu Kusrini, S.Pd juga memberikan keterangan sebagai berikut:

"Di juknis tugas dinas pendidikan mensosialisasikan kepada kepala sekolah, kemudian kami mengusulkan tapi usulan itu hanya memfasilitasi lewat sekolah jadi kami hanya "mengobrak-obrak". Kemudian yang mendapatkan PIP iti diprioritaskan pemegang KIP (pendistribusian darilembaga penyalur ke masyarakat jadi tidak lewat dinas pendidikan) tetapi manakala ada masyarakat yang tidak mendapatkan PIP, dan seharusnya masyarakat datang ke sekolah agar di ajukan lewat dapodik. Jikalau tidak keluar pada tahap 1 bisa juga keluar di tahap 3 dan ada juga tahap 1 dan 7 keluar karena sekolah tidak tahu dan orang tua "ngriseni' (buru-buru) pihak sekolah mengusulkan lagi. Mestinya kalu sudah diusulkan jangan di usulkan lagi."

(Wawancara, 13 Desember 2016)

Berdasarkan keterangan dari Kepala Seksi Kurikulum TK/ SD Dinas Pendidikan Kabupaten Rembang tersebut maka sekolah sebagai lembaga pendidikan, kaitannya dalam Program Indonesia Pintar (PIP) ini memiliki fungsi dan peranan yang penting. Fungsi dan peranan tersebut sangat membantu dalam proses pelaksanaan dan kesuksesan Program Indonesia Pintar (PIP) tepat sasaran, tepat waktu dan tepat jumlah dan tepat guna.

Guna mengantisipasi adanya penyelewengan dana ini, pihak Dinas Pendidikan telah melakukan pengawasan, sebagaimana hasil wawancara Kepala Seksi Kurikulum TK/ SD Dinas 


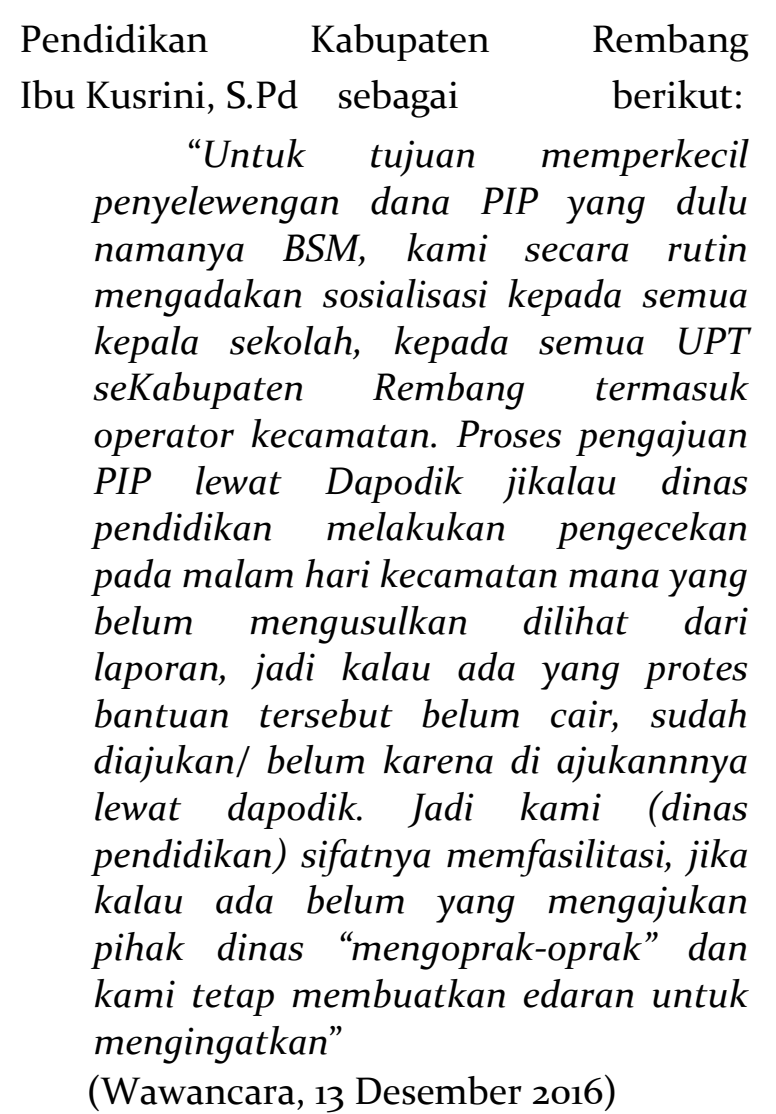

Kendala yang Menghambat Keberhasilan Program Indonesia Pintar di Kabupaten Rembang

Sebagaimana diketahui bahwa Program Indonesia Pintar (PIP) ini sangat baik dan memang terbukti mampu memberikan bantuan kepada keluarga tidak mampu untuk dapat tetap menyekolahkan anaknya hingga jenjang pendidikan menengah.Namun demikian pelaksanaan program ini tidaklah terlepas dari berbagai hambatan dan kendala yang dapat mempengaruhi kesuksesan program tersebut. Salah satu bentuk kendala yang dihadapi seperti sudah dikemukakan di atas yaitu adanya warga yang seharusnya mendapatkan program tersebut tetapi ternyata tidak bisa karena kendala administrasi atau bahkan ada keluarga yang seharusnya mampu tetapi justru bisa mendapatkan dana Program Indonesia
Pintar (PIP). Kesalahan-kesalahan tersebut tidak terlepas dari beberapa kelemahan.

\section{Kendala pelaksanaan Program Indonesia} Pintar (PIP) berdasarkan keterangan Kepala SD N Magersari Kabupaten Rembang

Pelaksanaan Program Indonesia Pintar (PIP) ini tentunya tidak terlepas dari adanya kendala dan hambatan. Seperti diungkapkan oleh Kepala SD N Magersari Kabupaten Rembang Ibu Luhur Sudaryanti, S.Pd bahwa:

"Kendala yang ditemukan adalah kesulitan dalam mendata siswa yang tidak mampu tetapi belum mempunyai KIP dan dilaporkan ke dinas"

(Wawancara, 5 Desember 2016)

Keadaan seperti ini kemudian akan mempersulit siswa untuk mendapatkan dana Program Indonesia Pintar (PIP), karena masalah kelengkapan administrasi. Sebagai salah satu contohnya adalah peserta Program Indonesia Pintar (PIP) terintegrasi dari peserta Kartu Indonesia Pintar (KIP).Kondisi seperti ini biasanya terkendala pada saat dilakukan sosialisasi.Dimana orang tua yang diundang pihak sekolah tidak bisa datang untuk mendengarkan penjelasan mengenai Program Indonesia Pintar (PIP).Sehingga persyaratanpersyaratan yang harus diajukan ketika mengajukan susulan Program Indonesia Pintar (PIP) tidak bisa dilengkapi sesuai ketentuan.

Sekolah harus mampu bertindak transparan dalam memberikan informasi dan meyakinkan kepada masyarakat untuk dapat dipercaya, agar tidak ada timbul fitnah yang berkepanjangan, selain itu agar Program Indonesia Pintar (PIP) di Kabupaten Rembang dapat dirasakan oleh siswa - siswi yang benar - benar dari keluarga ekonomi ke bawah. 
Kondisi lain yang cukup menjadi kendala bagi sekolah dalam melaksanakan Program Indonesia Pintar (PIP) sehingga tepat sasaran adalah sosialisasi yang tidak dapat tersampaikan kepada wali murid. Hal ini disebabkan karena saat dilakukan sosialisasi wali murid tidak bisa hadir ke sekolah untuk memenuhi undangan sosialisasi tersebut. Sebagaimana dinyatakan oleh Kepala SD N Magersari Kabupaten Rembang Ibu Luhur sudaryanti, S.Pd:

"Saat sekolah mengadakan sosialisasi tentang penerimaan PIP banyak orang tua siswa yang tidak datang"

(Wawancara, 5 Desember 2016)

Hal ini yang akhirnya mengakibatkan orang tua murid banyak yang tidak paham tentang Program Indonesia Pintar (PIP), cara penerimaannya, syarat-syarat yang dibutuhkan dan sebagainya. Pihak sekolah sudah memberikan undangan tertulis bagi orang tua murid, seperti pernyataan Kepala SD N Magersari Kabupaten Rembang Ibu Luhur Sudaryanti, S.Pd:

"Sekolah sudah memberi surat pemberitahuan kepada orang tua siswa" (Wawancara, 5 Desember 2016)

\section{Kendala Pelaksanaan Program Indonesia Pintar (PIP) berdasarkan Keterangan Wali Murid SD N Magersari Kabupaten Rembang}

Sosialisasi penerimaan Program Indonesia Pintar (PIP) kepada wali murid yang tidak berjalan dengan baik, yaitu ada wali murid yang tidak bisa hadir saat sosialisasi sehingga ditemukan berbagai kendala dan hambatan bagi wali murid yang tidak bisa hadir.Tanggapan yang beragam tersebut secara garis besar dikategorikan menjadi dua yaitu ditemukan adanya kendala dan tidak ditemukan adanya kendala. Wali murid yang menganggap ada kendala dan merasa kesulitan dalam pengurusan penerimaan Program Indonesia Pintar (PIP) ini ditemukan sebanyak 11 orang tua wali murid (44\%) yang merasa tidak terkendala dan yang menemui kesulitan sebanyak 14 orang tua wali murid (56\%).

Salah satu pernyataan dari wali murid mengatakan sebagai berikut:

"Saya cukup kesulitan, karena saya belum mengetahui tentang syarat-syarat dalam program PIP. Jadi kendalanya yaitu belum mengetahui tahap-tahap penerimaan PIP secara pribadi"

(Wawancara, 3 Desember 2016)

Sementara keterangan dari informasi wali murid yang lain menjelaskan sebagai berikut:

"Tidak ada permasalahan, karena persyaratannya sangat mudah, jadi tidak ada kendala apapun"

(Wawancara, 3 Desember 2016)

Dalam implementasi suatu program, karakter dari para agen pelaksana program harus berkarakteristik keras dan ketat pada aturan serta taat pada sanksi hukum yang berlaku.

Berdasarkan pengamatan peneliti bahwa agen pelaksana Program Indonesia Pintar (PIP) sebenarnya telah berusaha untuk menegakkan peraturan yang ada agar Program Indonesia Pintar (PIP) dapat berjalan sesuai aturan, salah satunya adalah dengan dilakukanya verifikasi data yang ketat, sehingga Program Indonesia Pintar (PIP) ini benar-benar dapat diperuntukkan bagi keluarga yang tidak mampu untuk keperluan personal sekolah anak dan tidak salah sasaran dalam memberikan manfaat Program ini. 
Kendala Pelaksanaan Program Indonesia Pintar (PIP) berdasarkan keterangan Kepala Seksi Kurikulum TK/ SD Dinas Pendidikan Kabupaten Rembang

Kendala yang ditemukan berkaitan dengan pelaksanaan Program Indonesia Pintar (PIP) ini adalah ditemukannya berbagai penyimpagan. Penyimpangan dapat diartikan sebagai kesalahan sasaran juga ada program-program selipan dari sekolah pada saat pencairan dana Program Indonesia Pintar (PIP) berlangsung. Berikut kutipan wawancara dengan Kepala Seksi Kurikulum TK/ SD Dinas Pendidikan Kabupaten Rembang Ibu Kusrini, S.Pd:

"Misal 100 anak, tahap 1 keluar 6o anak, 40 tidak dapat, sekolah bingung dan ada desakan dari komite dan wali murid terus diratakan. Per anak mendapatkan 450.00o di kasih kepada anak yang medapatkan PIP 300.000 kemudian 100.ooo di kasihkan kepada anak yang tidak mendapatkan PIP. Pihak dinas mengatakan itu tetap saja namanya memotong walaupun itu dikatakan sodaqoh tapi manakala ada seperti itu pihak dinas mengatakan tetap harus dikembalikan. Mestinya yang belum mendapatkan diajukan lagi kalau sudah diajukan dia harus menunggu manakala nanti waktunya tiba dia akan mendapat asal waktu mengajukan sesuai. Sekolah punya program misal membuat pagar, terus menyampaikan program itu pas menyampaikan sosialisasi PIP mau cair, contoh senin dana PIP cair jumat buat program mengumpulkan wali murid, begitu wali murid mendapatkan PIP wali murid iuran. Sekolah tidak diperkenankan memungut apapun, kalau menerima hibah dari mayarakat boleh"

(Wawancara, 13 Desember 2016).
Kendala - kendala tersebut juga berkaitan dengan komitmen dan sumberdaya yang ada.Sumberdaya merupakan faktor penting agar implementasi kebijakan berlangsung efektif.Hal ini didasarkan bahwa sumberdaya sebagai faktor yang sangat penting dalam pelaksanaan suatu kebijakan. Tanpa adanya sumberdaya, kebijakan hanya akan menjadi wacana dan dokumen saja, dengan adanya sumberdaya yang memadai kebijakan atau program akan terlaksana dengan tahapan-tahapan yang terorganisir. Kemampuan dan keterampilan dari agen pelaksana juga ikut menentukan keberhasilan suatu program.

\section{SIMPULAN}

Pelaksanaan Program Indonesia Pintar di Kabupaten Rembang telah dilaksanakan dengan baik yang dibuktikan dengan telah disalurkannya dana PIP bagi warga tidak mampu untuk keperluan sekolah anaknya hingga mencapai pendidikan menengah. Semua tahapan PIP sudah dilaksanakan mulai dari sosialisasi, usulan, verifikasi hingga penyaluran dana PIP. Pelaksanaan PIP di Kabupaten Rembang masih menemui hambatan dan kendala seperti belum dapat tersalurkannya dana ke masyarakat yang memang benar-benar membutuhkan atau salah dalam penyaluran kepada masyarakat yang sebenarnya tidak berhak, hal ini disebabkan karena kendala administrasi. Selain itu kendala juga ditemukan pada sumberdaya manusia. Sumber daya program program PIP sangat perlu diperhatikan dari segi kualitas agar memberikan pelayanan terbaik kepada calon PIP. Sumberdaya yang memadai dan kompeten perlu dipersiapkan dalam pelaksanaan verifikasi 
data untuk mengetahui kondisi latarbelakang perekonomian peserta didiknya sehingga tidak salah sasaran dalam melakukan verifikasi dan memberikan data calon peserta PIP secara akurat. Masyarakat hendaknya memaknai program ini sebagai salah satu upaya pemerintah dalam memberikan bantuan pendidikan kepada siswa hingga jenjang menengah, sehingga tidak mengambil keuntungan dari program ini untuk kepentingan-kepentingan yang diluar keperluan sekolah, atau bahkan bagi keluarga yang tidak seharunya menerima bantuan dari PIP tidak berupaya untuk mengajukan bantuan.

\section{DAFTAR PUSTAKA}

Ismaniar, Aisyah Rizqi. 2017. "Implementasi Kebijakan Tarif Angkutan Umum Jenis Mobil

Penumpang Umum Di Kota Semarang”. Dalam Economics Development Analysis
Journal 6 (1). Semarang: Universitas Negeri Semarang.

Noor, Henry Faizal. 2013. Ekonomi Untuk Kesejahteraan Rakyat. Padang: @kademia

Peraturan Menteri Pendidikan dan Kebudayaan Nomor 12 Tahun 2015 tentang Petunjuk Teknis Program Indonesia Pintar (PIP).

Peraturan Pemerintah Republik Nomor 47 Tahun 2008 yang dimaksud Wajib Belajar 9 Tahun.

Sugiyono. 2012. Metode Penelitian Pendidikan. Bandung: Alfabeta.

---2013. Metode Penelitian Pendidikan. Bandung: Alfabeta.

Undang-Undang Republik Indonesia Nomor 32 Tahun 2004 Tentang Pemerintahan Daerah.

Undang-Undang Republik Indonesia Nomor 23 Tahun 2014 Tentang Pemerintahan Daerah.

Undang-Undang Republik Indonesia Nomor 9 Tahun 2015 Tentang Perubahan Kedua Atas UndangUndang Nomor 23 Tahun 2014 Tentang Pemerintahan Daerah.

Noor, Henry Faizal. 2013. Ekonomi Untuk Kesejahteraan Rakyat. Padang: @kademia

Peraturan Menteri Pendidikan dan Kebudayaan Nomor 12 Tahun 2015 tentang Petunjuk Teknis Program Indonesia Pintar (PIP).

Peraturan Pemerintah Republik Nomor 47 Tahun 2008 yang dimaksud Wajib Belajar 9 Tahun. 